\title{
Ehlers-Danlos Syndrome or Disease?
}

Keywords: Ehlers-Danlos Syndrome; J oint hypermobility; Ehlers Danlos classification; Medical nosology; Definition of disease; Definition of syndrome

\section{Abstract}

Although first described in 1892 by Tschernogobow in Moscow, the medical history of Ehlers-Danlos syndrome (EDS) begins with Edward Ehlers's description in 1900 in Copenhagen. Several avatars would come to stymie its identification to this day, despite its frequency, and foster confusion with other pathologies. The first of these is the description by Alexandre Danlos (1908), who particularly emphasized a sign: excessively stretchable skin which would become solidly anchored in the minds of doctors who, even today, use it to rule out the diagnosis if it is not found. In 1933, in Paris, Achille Miget based his doctoral thesis (Syndrome d'Ehlers-Danlos) in medicine on a new case, and expressed doubts about the identity of Danlos'case. This case is, in fact, a Pseudoxanthoma elastic um. The second avatar was the introduction of identification and classification based on mutations of various collagens, by associating one or several types of collagen with a set of clinical manifestations. The clinical differences between the various types are tenuous; excessive skin stretch ability and hypermobility are found in both the classical form and hyper mobile forms, aneurysms, can be found in every type of EDS. Rheumatologists first addressed this syndrome on the basis of hypermobility, describing it as benign. Prof. Grahame was the first to make a shift in the clinical perception of the syndrome and progressively added other manifestations (i.e. pain). They thus bridged the gap between joint hypermobility syndrome and EDS-hyper mobile type. Now EDS appears as a reliable clinical entity, characterized by patterns of easy-to-identify clinical symptoms, which have very strong diagnostic value, when taken together with the existence of similar cases in a patient's family. We describe it from 644 of our first patients (out of 2,213 patients). We have selected certain signs which are particularly significant in terms of their frequency and because they agree with signs also described by other authors: diffuse pains, fatigue and problems with vigilance, joint hypermobility, fragility of skin, tendency to haemorrhages, proprioceptive disturbances, dystonia, constipation, gastro-oesophagal reflux, dyspnea, sensations of respiratory blockage, dysautonomia, oral/ dental, ENT, visual symptoms, and cognitive difficulties. It has been proposed a discussion about the choice of syndrome or disease for Ehlers-Danlos, the semiological anarchy may have originated in the method for identifying diseases (the nosology) set up in the $18^{\text {th }}$ century by physicians who were also botanists (i.e. Boissier de Sauvages, 1771; Cullen, 1769; Linnaeus, 1759). The syndrome is "a list of symptoms that are not necessarily related to specific diseases" (Littré, 1875). The usual medical culture perceives a disease as an entity that has an etiological basis, which presents a characteristic clinical picture, and which requires appropriate treatment. This is the case for Ehlers-Danlos Disease, a term that should be preferred to that of EDS.

\section{Birth and Evolution of the Concept of EDS}

Although first described in 1892 by Tschernogobow in Moscow [1], the medical history of this syndrome only truly begins with its first and excellent description on December 15, 1900 by Edward Ehlers in Copenhagen [2], based on the case of a law student, and presented to the Danish Society of Dermatology and Syphiligraphy. This observation, though brief, was very precise, and pointed out several of the most important clinical signs that, even nowadays, allow diagnosis: joint hypermobility, skin fragility, and haemorrhages. Subsequently, several avatars would come to stymie its identification
Journal of Syndromes

\section{Hamonet ${ }^{1,2 *}$, A. Gompel ${ }^{3}$, G. Mazaltarine ${ }^{4}$, I. Brock $^{1}$, C. Baeza-Velasco ${ }^{5}$, J.D Zeitoun ${ }^{6}$ and B. Bienvenu $^{\mathrm{B}}$}

${ }^{1}$ Consultation Ehlers-Danlos, Hôtel-Dieu de Paris, France ${ }^{2}$ Faculté de Médecine de Créteil, Université Paris-Est-Créteil, Créteil, France

${ }^{3}$ Unité fonctionnelle: Endocrinologie Gynécologique, CHU Paris Centre - Hôpital Cochin, Paris, France

${ }^{4}$ Service de Rééducation Neuro-orthopédique, Hôpital Henri Mondor, Créteil, France

${ }^{5}$ Institut de Psychologie, Université Paris Descartes, Sorbonne Paris Cité, Boulogne-Billancourt, France

${ }^{6}$ Groupe Hospitalier Diaconesses Croix Saint-Simon, Paris, France ${ }^{7}$ Service de Médecine Interne, CHU de Caen, Hôpital de la Côte de Nacre, Caen, France

\section{*Address for Correspondence}

C. Hamonet, Consultation Ehlers-Danlos, Hôtel-Dieu de Paris, France, 1 place du Parvis Notre-Dame, 75181, Paris Cedex 04, France, E-mail: pr.hamonet@wanadoo.fr

\section{Submission: 17 May 2015}

Accepted: 21 July 2015

Published: 27 July 2015

Copyright: ( 2015 Hamonet C, et al. This is an open access article distributed under the Creative Commons Attribution License, which permits unrestricted use, distribution, and reproduction in any medium, provided the original work is properly cited.

to this day, despite its frequency, and foster confusion with other pathologies with which it shares certain clinical manifestations.

The first of these confusions is the description made in 1908, by Alexandre Danlos to the French Society of Dermatology in Paris [3], of "A case of cutis laxa with chronic contusions tumors of elbow and knees (Pseudo-juvenile diabetic xanthoma) from MM Hallopeau and Macé de l'Epinay". Danlos particularly emphasized a sign which would become solidly anchored in the minds of doctors who, even today, use it to rule out the diagnosis if it is not found: excessively stretchable skin, which he wrongly compared with rubber. Wrongly so, because one of the principal factors leading to the symptoms of Ehlers-Danlos Syndrome is precisely the reverse: it is the loss of the connective tissues elasticity [4].

In 1933, in Paris, Achille Miget based his doctoral thesis in medicine on a new case, giving it the name of the two first doctors to describe it. Ehlers-Danlos Syndrome (EDS) was born [5]. And yet, Miget had doubts about the identity of Danlos' case. He found the patient and took a biopsy of his skin. He noted that the histopathology of this case differed from the case described in his thesis. These findings, together with the fact that the skin of Danlos' patient was highly stretchable, more so than is commonly found in this syndrome, leads us to conclude that the case described by Danlos was in fact, a Pseudoxanthoma elasticum [3]. Unfortunately, what many doctors remember about the syndrome is the idea that significant skin stretch ability is a requisite for diagnosis, believing that its absence must rule out the diagnosis. As a result, a very large number of patients were and will continue to be deprived of diagnosis.

The second avatar was the introduction of genetics into its history. The hereditary nature suspected in Ehlers' initial diagnosis, 
was recognized early on. It led to attempts at identification and classification based on mutations of various collagens, by associating one or several types of collagen with a set of clinical manifestations. These classifications have evolved over time. The most recent, known as the Villefranche classification [6], distinguishes six forms: classical type, hyper mobile type, vascular type, kyphoscoliosis type, arthrochalasia type, and dermatosparaxis type. The clinical differences between these various types are tenuous; excessive skin stretch ability and hypermobility are found in both the classical form and the hyper mobile form. It is almost impossible to draw a clinical distinction between the two in practice, and it makes no difference, either way; the consequences in terms of disability, precautions to be taken, symptomatic treatment, prognosis, and genetic transmission are the same. The terminology proposed at Villefranche [6], leads to confusion because the hypermobility, that is the predominant feature in both forms, may also be absent or have disappeared with age [7], and retractions are possible as well [8]. In addition, the term, "classical" leads one to believe that it is the most common form, whereas those who continue to defend it as a separate form agree that it is infrequent and that the usual form is the hyper mobile type [9]. As yet, however, no specific collagen mutation has been found to be associated with it. Hypermobility, which was considered by many geneticists to be an absolute prerequisite for the diagnosis of EDS, is often assessed using the 9-point Beighton score [10]. A Beighton score equal to or greater than 4 is suggestive of hypermobility. However this test is often misleading or poorly applied; it considers only a small number of joints [11], it does not take into account pain or muscle contractures, and therefore wrongly rules out a large number of patients. Thus a negative score is not incompatible with a positive diagnosis, especially in adults [7]. Although less numerous, studies in children often use the Beighton score. A recent study using this method, found that hyper mobile children had three times higher risk of developing joint pain in adolescence [12].

Methodological aspects, such limits of Beighton score, have introduced a considerable amount of confusion into the clinical diagnosis of EDS, with the result that even today this very common pathology continues to be considered, against all odds, to be rare. Indeed, it is almost never mentioned and it is constantly confused with other diagnoses that impose aggressive medical or surgical treatments on patients whose primary characteristic is their fragility in case of aggressive surgical and medical treatment.

This semantic confusion was further exacerbated with the recent emphasis [13], on the so-called vascular forms (EDS-vascular), in which aneurysms and arterial dissection are particularly frequent. These forms can be genetically identified by the frequent mutation of the COL3 A1 gene. Their clinical description overlaps with many manifestations found in other forms of EDS: thinness of the skin, intestinal and uterine fragility, easy bruising, smooth facial appearance (the so-called "portrait of the Madonna") which is very often found in the other forms, in which a person may have no wrinkles, giving the impression that they are, on average, ten years younger than they really are. Similarly, aneurysms may occur in all forms of the syndrome, and should be systematically screened for, with sonography, with, if necessary, an artery scan or brain MRI. Fortunately, these so-called "lethal" forms by those that described them [13] are exceptionally rare. Their diagnosis though is often a source of stress for both patients and doctors who are basing their conclusions on signs which exist in all the ordinary forms of the syndrome (e.g. the tendency to haemorrhage). This emphasis on the severity of certain manifestations of EDS and the multiplicity of publications on the subject have led many doctors to focus only on these more severe but very rare forms, and to neglect the more frequent forms, believing that they have few, if any, functional consequences. This attitude has led to a lack of interest and to the denial of the more frequent forms of EDS, which may nonetheless cause serious disability. EDS patients have been abandoned, even ostracized, by much of the medical community. Their symptoms are labeled psychosomatic or even imputed to severe mental illness, sometimes leading to powerful psychiatric treatment, resulting in destructive iatrogenic and social effects. Grahame stated "to my knowledge, there is no other illness that has been so neglected-the patients are much more familiar with it than their doctors" [14].

Rheumatologists first addressed this syndrome on the basis of hypermobility. Grahame, Gazit, Bravo and Bulbena were among the first to make a shift in the clinical perception of the syndrome and progressively added other manifestations (such as pain, dysautonomia, pathological anxiety and digestive disturbances) and found functional limitations which were the cause of disability [11,15-17]. They thus bridged the gap between joint hypermobility syndrome and EDS-hyper mobile type [18], resulting in a reliable clinical entity, characterized by patterns of easy-to-identify clinical symptoms which have very strong diagnostic value on their own and when taken together with the existence of similar cases in a patient's family.

Clinical practice reveals a high frequency of EDS, but heterogeneity of evaluation systems does not allow knowing the prevalence of the syndrome. However some interesting data are available. Grahame and Hakim reported a prevalence of $45 \%$ in patients from a rheumatologic clinic in England [19]. Bravo and Wolff observed a prevalence of 39\% in Chile, and we estimated that 1 million people are affected in France $[16,20]$.

\section{Up-to-date Clinical Practice for EDS}

Based on a statistical analysis of 644 of our first patients (out of 2,213 patients in 16 years) [21], we have selected certain signs which are particularly significant, both in terms of their frequency and because they agree with signs that have been described by other authors [22,23]. EDS is a collagen disorder that affects all of a person's connective tissue. It causes these tissues to be less resistant (e.g. skin fragility, fragility of small vessels, easy bruising, and osteopenia) and lose their elasticity, thereby disrupting the signals sent by receptors situated in connective tissue (such as pain, proprioceptive dysfunction, dysautonomia, and dystonia) [24]. Concerning pain, it is well known that the pain experience may be modulated by psychological factors (e.g. emotional, cognitive) [25]. In this regard, patients with hereditary disorders of the connective tissue, especially Ehlers-Danlos syndrome hypermobility type, have a tendency to suffer from pathological anxiety and other negative emotions, as well as enhanced interoception and somatosensory amplification [26]. These aspects may contribute to increase the painful experience.

It is necessary to understand this mechanism in order to grasp the symptomatology and determine appropriate treatment. The specific nature of the connective tissue explains the wide diversity of 
symptoms, which, when taken together, are sufficiently evocative of the syndrome. This approach is contrary to that which many doctors still use, as a result of their medical training, which is to address disease in one organ at a time. They have great difficulty in taking a systemic and holistic approach, and in making a diagnosis on the basis of clinical symptoms alone. The contribution of genetics, with the exception of the forms involving multiple aneurysms, remains very limited and, indeed, is useless in the diagnosis of the forms most commonly found.

Main symptoms observed in 644 of our patients:

- Diffuse joint pain (98\%), pain in muscles (80\%), skin, and abdomen (77\%), thoracic pain (66\%), genital pain and migraines $(87 \%)$ which may be variable and often resist analgesic medicines, even powerful ones.

- Fatigue and problems with vigilance (98\%) with spells of sleepiness and feelings of exhaustion, even upon waking.

- Joint hypermobility (96\%) which is not always spectacular and which diminishes with age (Beighton score equal to or greater than 4/9).

- Skin fragility (97\%) which may take several forms: frequent excoriation of the skin (83\%), slow and difficult wound healing (73\%), early and/or abundant stretch marks (74\%), soft, velvety skin (74\%).

- Highly stretchable skin is absent in $31 \%$ of cases. There is less resistance to transmission of electricity, and patients may feel electric shocks upon contact with metal objects (we call it "the car door sign" as patients very often and even in summer get a small electric shock when opening the car door).

- Tendency to haemorrhages (91\%). This is due to the weakness of the blood vessel walls and is expressed by the seemingly spontaneous appearance of bruises and hematomas, bleeding of the gums, nosebleeds, very abundant menstrual bleeding, bronchial bleeding, or digestive bleeding, which, in addition with the organ's wall weakness make patients vulnerable to accidents during endoscopies.

- Proprioceptive disturbances (98\%), with difficulty in perceiving the body and in controlling movements, and which are evidenced by subluxations, sometimes confused with sprains, missteps, legs giving way when walking, bumping into things or people (such as doorframes, in particular: "the door sign"), falling down, clumsiness (dropping things), and pseudo-paralytic presentations and/ or a complete lack of sensation in a part of the body. We have also observed dystonic-type movements (involuntary startle movements, clonic movements, trembling, and sometimes intense pseudo-epileptic contractions), which resolve with antiparkinson treatment.

- Constipation (72\%), which may be severe, and lead to occlusions, which in turn may lead to medical intervention. It may alternate with diarrhea.

- Gastro-oesophagal reflux (76\%) with multiple concomitant complications affecting the airways.
- Dyspnea (83\%) arising as a result of insignificant effort ("the staircase sign").

- Frequent sensations of respiratory blockage with inspiration, bradypnea occurring at random.

- Dysautonomia is frequent, with feelings of cold extremities ("the sock sign"), low blood pressure, sweating (as described by Ehlers), changes in heart rate (bradycardia at rest, stressful episodes of tachycardia).

- Oral/dental, ENT, and visual manifestations are frequent as well.

- Cognitive difficulties (e.g., difficulties with working memory, attention, concentration, and orientation) are frequently associated, as well as sleep disturbances.

Onset of these manifestations often takes place in childhood, in a different order for each patient, and with variable intensity. Most often, there are acute episodes arising out of a background of chronic discomfort. Certain factors cause symptoms to significantly worsen: trauma, hormonal fluctuations ( $80 \%$ of our patients are women), variations in the weather (especially cold and humid weather), and insufficient physical exercise.

\section{Ehlers-Danlos: A Syndrome or a Disease? A challenge for Medical Semiotics Arising from Botany}

There is currently some confusion about the terms "disease" or "syndrome" in both medical usage as well as the vernacular. For instance, fibromyalgia is spoken of as a disease, whereas it consists of symptoms involving pain in muscles and tendons. The terms "disease" or "syndrome" are interchangeable in the case of "restless legs", and the diagnosis of "chronic fatigue" needs no qualifier. This lack of precision in the medical vocabulary led the celebrated French semiologist Roland Barthes, to speak quite harshly of medical semiology, stating that it was not semiology and that he could not understand medical descriptions [27]. This brutal conclusion requires that we take another look at medical practice and the way we use words and concepts to create a special doctor/patient relationship in order to, together, arrive at a diagnosis. A new way on how we establish proper doctor patient communication, a constructive dialogue expressing the patient's experience (the symptoms) and the doctor's interpretation is needed. Signs can then be re-interpreted and when taken together, will permit the identification of a clinical entity (disease or syndrome), which will result in the offer of appropriate treatment. This apparent semiological anarchy may have originated in the method for identifying diseases (the nosology) set up in the $18^{\text {th }}$ century by doctors who were also botanists (Linnaeus in Sweden, Boissier de Sauvages in France and Cullen in England). The "Methodical nosology, in which Disease are Sorted by Categories, Following Sydenham's System, as well as that of Botanists" (1756 in latin, 1771, in French) [28]. Within "Boissier's tables" or tableaux, (thus giving rise to the expression, "clinical picture") for each class, there are subsets (orders) which are really clinical forms, but which are closer to certain classes (class VII, Pain) in the representation of a syndrome. The term "syndrome" does not, however, appear in Boissier's writings and commentary. There is continuity between Boissier's Classification and the current classification of diseases used by the WHO [29]. The principle of classifications remains 
omnipresent in the description of diseases. EDS is an example when seen in the light of the classifications made by geneticists and used as a diagnostic tool. The word "syndrome" comes from the Greek: sun dromein, meaning, "to go or race together". It applies well to the definition given to it by Emile Littré, who was trained as a physician: "the name that the ancient Greeks gave to lists of symptoms that are not necessarily related to specific diseases" [30]. Therefore, it is the notion of a etiology that distinguishes a syndrome from a disease. Paradoxically, certain aspects that are specific to the vascular form of EDS were connected to the term, "the Ehlers-Danlos Syndromes".

The definition of disease is relative "In order to precisely define disease in general, one must first know what health is" [30], "Changes in health" [31]. This is an important point in EDS because the presenting symptoms are banal and are part of daily life: fatigue, sleep disturbances, dizziness, pain, digestive difficulties, clumsiness, etc. Such symptoms are all too often dismissed or not believed by doctors. It is their intensity, the fact that they exist together, and their persistence that should retain one's attention and lead to a diagnosis, thereby distinguishing what is normal from what is pathological One aspect should be borne in mind, which is how the terms utilized resonate in the mind: the concept of "syndrome" remains vague in the minds of most people, and does not contribute to consolidating the reality of a pathology which is disabling and which disrupts day-today life, often requiring drastic precautions to be taken. In general, the medical culture perceives a disease as an entity that has an etiological basis, which presents a characteristic clinical picture, and which requires appropriate treatment. Ehlers-Danlos exactly fulfils these conditions, and therefore should be considered as a disease: it is familial in nature it is transmissible, it has a clearly-defined clinical picture, and enables diagnoses to be made with a very high degree of certainty, appropriate treatments do exist, and there are also precise precautions and contraindications. The nosologic problems that arise when an actual disease is called a syndrome can well be exemplified by Ehlers-Danlos Syndrome.

\section{Conclusion}

Ehlers-Danlos is a familial, transmissible pathology of connective tissue, resulting from defective protein synthesis [32]. These alterations are responsible for numerous clinical manifestations (e.g., pain, joint disorders, fatigue, skin fragility, haemorrhages, digestive problems, ENT problems, respiratory problems, dysautonomia, dystonia, bladder and sphincter problems, oral and dental problems, and cognitive disturbances). In addition, it does not appear to be a rare disease; instead, it is actually frequent, despite the fact that many doctors are highly unfamiliar with it, thereby causing numerous iatrogenic complications. Physicians' lack of knowledge about Ehlers-Danlos syndrome is the result of random and incomplete descriptions, which, fortunately, are beginning to be corrected in the international medical literature. Although it is known as a syndrome, it is in fact a disease whose diagnosis may be made with certainty on the basis of a set of clinical manifestations alone. Genetic tests are most often inconclusive as regards to the types of cases most often seen in clinical practice. Significant efforts have yet to be made on the international level, in order to build awareness to the disease and its treatments, and to help affected families who are all too often rejected and excluded.

\section{References}

1. Tschernogobow A (1892) Cutis Laxa (Presentation at first meeting of Moscow). Dermatologic and Venereology Society. Monatshefte für Praktische Dermatologie 14: 76.

2. Ehlers E (1901) Cutis laxa, Neigung zu Haemorrhagien in der Haut. Lockerung mehrerer Articulationen. Derm Zschr 8: 173-174.

3. Danlos HA (1908) Un cas de cutis laxa avec tumeurs par contusion chronique des coudes et des genoux (Xanthome juvénile pseudo-diabétique de MM. Hallopeau et Macé de lepinay). Bull Soc Fr Derm Syph 19: 70-72.

4. Beighton P, Grahame R, Bird H (1983) Hypermobility of joints (4 $4^{\text {th }}$ edn). Springer London.

5. Miget A (1933) Le Syndrome d'Ehlers-Danlos (Thèse pour le doctorat, Universite de Paris, Nr 321-1933). Broche originale in $8^{\circ}$, bon etat. Louis Arnette, Paris.

6. Beighton P, De Paepe A, Steinmann B, Tsipouras P, Wenstrup RJ (1998) Ehlers-Danlos syndromes: revised nosology, Villefranche, 1997. EhlersDanlos National Foundation (USA) and Ehlers-Danlos Support Group (UK). Am J Med Genet 77: 31-37.

7. Castori M, Sperduti I, Celleti C, Camerota F, Grammatico P (2011) Symptom and joint mobility progression in the joint hypermobility syndrome (EhlersDanlos syndrome, hypermobility type). Clin Exp Rheumatol 29: 988-1005.

8. Hamonet C, Brock I (2015) Joint mobility and Ehlers-Danlos syndrome, (EDS) new data based on 232 cases. J Arthritis 4: 5 .

9. Levy H (2004) Ehlers-Danlos syndrome, hypermobility type. GeneReviews $₫$ [Internet].

10. Beighton P, Solomon L, Soskolne CL (1973) Articular mobility in an African population. Ann Rheum Dis 32: 413-418.

11. Keer R, Grahame R (2003) Hypermobility syndrome: Recognition and management for physiotherapists. Butterwoth Heinemann, London.

12. Sohrbeck-Nøhr O, Kristensen JH, Boyle E, Remvig L, Juul-Kristensen B (2014) Generalized joint hypermobility in childhood is a possible risk for the development of joint pain in adolescence: a cohort study. BMC Pediatr 14: 302.

13. Ong K-T, Perdu J, De Backer J, Bozec E, Collignon P, et al. (2010) Effect of celiprolol on prevention of cardiovascular events in vascular Ehlers-Danlos syndrome: a prospective randomised open, blinded-endpoints trial. Lancet 376: 1476-1484.

14. Grahame R (2015) Conclusions, First French-language international symposium, treatment of Ehlers-Danlos syndrome, Créteil Faculty of Medicine, University of Paris-Est-Créteil.

15. Gazit Y, Nahir AM, Grahame R, Jacob G (2003) Dysautonomia in the joint hypermobility syndrome. Am J Med 115: 33-40.

16. Bravo JF, Wolff C (2006) Clinical study of hereditary disorders of connective tissues in a Chilean population: joint hypermobility syndrome and vascular Ehlers-Danlos syndrome. Arthritis Rheum 54: 515-523.

17. Bulbena A, Duró JC, Mateo A, Porta M, Vallejo J (1988) Joint hypermobility syndrome and anxiety disorders. Lancet 2: 694

18. Tinkle BT, Bird HA, Grahame R, Lavallee M, Levy HP, et al. (2009) The lack of clinical distinction between hypermobility type of Ehlers-Danlos syndrome and the joint hypermobility syndrome (a.k.a. hypermobility syndrome). Am J Med Genet A 149A: 2368-2370.

19. Grahame R, Hakim A (2006) Joint hypermobility syndrome is highly prevalent in general rheumathology clinics, its occurrence and clinical presentation being gender, age and race-related. Ann Rheum Dis 65 (Suppl II): 263.

20. Hamonet C, Gompel A, Raffray Y, Zeitoun JD, Delarue M, et al. (2014) Multiple pains in Ehlers-Danlos syndrome. Description and proposal of a therapy protocol. Douleurs 15: 264-277.

21. Hamonet C, Ravaud P, Villeneuve S, Gompel A, Serre N, et al. (2012) 
Citation: Hamonet C, Gompel A, Mazaltarine G, Brock I, Baeza-Velasco C, et al. Ehlers-Danlos Syndrome or Disease? J Syndromes. 2015;2(1): 5.

Ehlers-Danlos: about 664 cases. Statistical analysis of clinical signs from 644 patients with a Beighton scale $\geq 4 / 9$. First international Symposium on the Ehlers-Danlos Syndrome, Ghent, Belgium.

22. Grahame R, Bird HA, Child, A (2000) The revised (Brighton 1998) criteria fo the diagnosis of benign joint hypermobility syndrome (BJHS). J Rheumatol 27: $1777-1779$

23. Colombi M, Dordoni C, Chiarelli N, Ritelli M (2015) Differential diagnosis and diagnostic flow chart of joint hypermobility syndrome/ehlers-danlos syndrome hypermobility type compared to other heritable connective tissue disorders. Am J Med Genet C Semin Med Genet 169C: 6-22.

24. Voermans NC, Knoop H, Bleijenberg G, van Engelen BG (2010) Pain in ehlers-danlos syndrome is common, severe, and associated with functiona impairment. J Pain Symptom Manage 40: 370-378.

25. Linton SJ, Shaw WS (2011) Impact of psychological factors in the experience of pain. Phys Ther 91: 700-711.

26. Bulbena A, Pailhez G, Bulbena-Cabré A, Mallorqui-Bagué N, Baeza-Velasco C (2015) Joint hypermobility, anxiety and psychosomatics: two and a half decades of progress toward a new phenotype. Adv Psychosom Med 34: 143 157.
27. Barthes R (1985) L'aventure sémiologique, vol. 219 Points (Éditions du Seuil): Série essais. Discourse analysis, the University of California, Paris.

28. Boissier de Sauvages F (1771) Nosologie méthodique: dans laquelle les maladies sont rangées par classes, suivant le système de Sydenham, et l'ordre des botanistes, University of Lausanne, Paris, chez Hérissant, vol. 2.

29. Hamonet C, Thomas LV, Université Paris Descartes (Paris) (1993) Handicapologie et anthropologie (Handicapology and anthropology). Lille: Atelier national de reproduction des Thèses, Paris.

30. Littré E (1875) Dictionnaire de la langue française: abrege du dictionnaire de E. Littre / par A. Beaujean. (Dictionary of the French language). Beaujean A (1801-1881), Librairie Hachette, Paris.

31. Maximilien S (1837) Médecine pratique. Bureau de l'Encyclopédie (the Encyclopedia of practical medicine), Paris.

32. Hakim A, Sahota A (2006) Joint hypermobility and skin elasticity: the hereditary disorders of connective tissue. Clin Dermatol 24: 521-533. 